\title{
Comparison of Bacteria Populations in Clean and Recycled Sand used for Bedding in Dairy Facilities
}

\author{
M. A. Kristula, ${ }^{1}$ W. Rogers, ${ }^{2}$ J. S. Hogan, ${ }^{3}$ and M. Sabo ${ }^{4}$ \\ ${ }^{1}$ University of Pennsylvania, School of Veterinary Medicine, New Bolton Center, Kennett Square 19348 \\ ${ }^{2}$ AET Consulting, Inc., Lititz, PA 17543 \\ ${ }^{3}$ OARDC, The Ohio State University, Wooster 44691 \\ ${ }^{4}$ P.O. Box 43, Unionville, PA 19375
}

\begin{abstract}
Bedding samples were collected twice from commercial dairy free-stall facilities that used recycled sand and clean sand in both the summer and winter. Collection began on the day sand was taken from the pile ( $d$ 0 ) and placed in the free stalls, and continued for 5 to 7 additional days. The number of colonies per gram of bedding of gram-negative bacteria, coliforms, Streptococcus spp., and Klebsiella spp. were estimated for each sand sample as well as amounts of dry and organic matter. Clean sand (CS) and recycled sand (RS) had the same bacterial counts when compared at any sampling time. The mean counts of bacterial populations did vary over the course of the study in both CS and RS. There was a significant increase in bacterial counts from $d 0$ to $\mathrm{d} 1$ for gram-negative bacteria, coliforms, and Streptococcus spp. in both winter and summer. Counts of gram-negative bacteria, coliforms, Klebsiella spp., and Streptococcus spp. did not differ from d 1 to 7 in the winter. Total counts of gram-negative bacteria did not differ from $d 1$ to 7 in the summer. On $d 1$ in the summer, coliform counts were lower than at d 5 to 7, and Klebsiella spp. counts were lower than on $\mathrm{d} 3$ to 7 . Streptococcus spp. counts were high on $\mathrm{d} 1$ and were constant through $\mathrm{d} 7$ in both winter and summer trials. The number of coliform and Klebsiella spp. in both CS and $\mathrm{RS}$ was below the threshold thought to cause mastitis during the sampling times. The number of Streptococcus spp. was high in both CS and RS during the sampling periods. Other management factors need to be identified to decrease the number of Streptococcus spp. in bedding. Recycled sand had a higher organic matter and lower dry matter compared with CS in winter and summer. The results for this study were obtained from multiple herd comparisons, and herd was a significant effect suggesting that different management systems
\end{abstract}

Received March 15, 2005.

Accepted August 5, 2005.

Corresponding author: M. A. Kristula; e-mail: kristula@vet.upenn. edu. influence the number and types of bacteria in both CS and RS.

(Key words: sand, recycled, bedding, dairy)

Abbreviation key: $\mathbf{C S}=$ clean sand, $\mathbf{R S}=$ recycled sand.

\section{INTRODUCTION}

Mastitis is a major health problem for dairy cows, with significant economic implications for the dairy industry. Economic losses in the United States are conservatively estimated to be $\$ 200$ per cow per year (DeGraves and Fetrow, 1993). Mastitis-causing pathogens are categorized as either contagious or environmental based on their primary reservoir in the dairy herd (Smith and Hogan, 2001). The primary reservoir of the contagious pathogens is the infected mammary gland, and pathogens are spread from infected to uninfected cows primarily during the milking procedure. Contagious pathogens can be controlled in dairy herds by teat dipping after milking, lactating and dry cow treatment, and by screening potential purchases for contagious pathogens.

The primary reservoir of environmental pathogens is the environment in which the cow is living. Environmental pathogens are the major causes of clinical mastitis in most dairy herds (Smith and Hogan, 2001). There has been less progress on control of mastitis caused by environmental pathogens compared with that caused by contagious pathogens (Smith and Hogan, 2001). Herds that have controlled contagious pathogens tend to experience high rates of mastitis caused by environmental pathogens.

The rate of intramammary environmental coliform infections in dairy cows is correlated with the number of bacteria on the teat end (Hogan et al., 1989), and the number of bacteria on the teat end is closely related to the number of bacteria in the bedding (Rendos et al., 1975; Natzke and LeClair, 1976; Hogan et al., 1989). Zdanowicz et al. (2004) reported moderate correlation between bacterial counts on the teat ends and bacterial counts in sawdust bedding, but a weaker correlation in 
sand bedding. High bacterial populations in bedding will result in high bacteria levels on the teat ends, resulting in increased environmental mastitis (Hogan et al., 1989). Therefore, designing housing and management systems that reduce exposure of environmental pathogens to the teat end will decrease mastitis caused by environmental pathogens.

Although a wide variety of materials have been used as free-stall bedding, inorganic bedding such as sand has been shown to have significantly lower bacterial numbers than organic bedding (Hogan et al., 1989) and is widely considered the best bedding for cow comfort. Recently both active (mechanical sand separator) and passive (gravity) manure systems have been developed that enable the sand to be separated from the manure. In most cases, the separated sand is recycled as bedding for the free stalls. Few studies have evaluated the safety of using recycled sand (RS) to bed dairy stalls, or compared the total bacterial populations in both clean sand (CS) and RS over $1 \mathrm{wk}$. Most dairy farmers bed stalls with sand once a week, so it would be valuable to know what happens to the bacterial populations in sand over time in the stall. There are potential economic, animal welfare, and environmental advantages of using RS if it is found to be a safe and acceptable bedding material. The objective of this study was to compare bacterial types and populations in both CS and RS from the time the sand was taken off the pile (d 0) until the stalls were rebedded with sand in $7 \mathrm{~d}$ (d 1 to 7 ).

\section{MATERIALS AND METHODS}

\section{Description of Data Collection: Winter}

In February and March 2003, samples of bedding sand were collected from 6 commercial dairy free-stall facilities that used RS and 6 that used CS. Collections began on the day sand was taken from the pile and placed in the free stalls $(\mathrm{d} 0)$ and continued for 5 to 7 additional days, after which stalls were re-bedded with sand. Composite samples were taken from the back onethird of $10 \%$ of the free stalls by the dairy farmers. The samples were frozen and packaged for later overnight delivery to the laboratory for analysis. Collections were replicated once at each facility, so that at each facility, bedding sand was sampled over 6 to $8 \mathrm{~d}$ on 2 separate occasions. The number of colony-forming units per gram of bedding of gram-negative bacteria, coliforms, Streptococcus spp., and Klebsiella spp. were estimated for each sand sample, as well as amounts of DM and OM. The particle-size composition of each sand sample taken from the pile was estimated by categorizing the percentage of sample weight that could be attributed to each of 4 particle-size categories.

\section{Description of Data Collection: Summer}

The procedure was repeated during July through September of 2003 at 4 facilities using RS and 7 facilities using CS. As in winter, sample collection began on the day when sand was taken from the pile $(\mathrm{d} 0)$ and continued for a period of 6 to $8 \mathrm{~d}$. Replicate samples were collected over a separate 6 - to 8 -d period at each facility. The same set of variables that were measured in the winter samples were measured in each sample collected during the summer months.

\section{Bacteriological Methods}

Ten grams of bedding was added to $90 \mathrm{~mL}$ of sterile PBS ( $\mathrm{pH} 7.0$ ) in a 500-mL plastic bag and mixed in a stomacher (Tekmar Company, Cincinnati, $\mathrm{OH}$ ) for 60 s. After contents had settled (2 to $3 \mathrm{~min}$ ), appropriate dilutions were plated on the surface of each of 3 media: MacConkey's agar (Difco Laboratories, Detroit, MI), MacConkey's-inositol-carbenicillin agar, and Edward's modified medium agar with $5 \%$ plasma. Four $10-\mu \mathrm{L}$ samples of each dilution were plated on 1 half plate containing each agar medium and incubated for $24 \mathrm{~h}$ at $37^{\circ} \mathrm{C}$. Bacterial groups were identified as gram-negative bacteria (total growth on MacConkey's agar), coliforms (lactose-positive colonies on MacConkey's agar), Klebsiella spp. (red to pink colonies on MacConkey'sinositol-carbenicillin agar), and Streptococci spp. (total growth on Edward's modified medium agar). Bacterial counts were expressed as $\log _{10} \mathrm{cfu} / \mathrm{g}$ of dry weight of sample.

\section{Laboratory Methods}

Dry matter analysis was performed by drying bedding material at $135^{\circ} \mathrm{C}$ for $2 \mathrm{hr}$ according to standard methods (AOAC, 1990). Organic matter analysis was performed according to the Walkley-Black method (Walkley-Black, 1995). To determine particle size, bedding material was air-dried and dry sieved using US Standard Number 20, 60, and 100 sieves (Fisher Scientific, Pittsburgh, PA). The number 20,60, and 100 sieves corresponded to 850,250 , and $150 \mu \mathrm{m}$ diameter mesh screen sizes. A fourth category $(-100)$ represented the sand left after sieving through the standard 20,60 , and 100 sieves.

\section{Statistical Analyses}

The objectives were to 1 ) test for differences between treatment groups (RS and CS) in observed bacterial populations and DM and OM composition in winter and summer samples, accounting for variation attributable to trials and repeated measures; 2) test for changes 
among the repeated measures (days) in bacterial populations and DM and OM composition in winter and summer samples; and 3) test for differences between treatment groups (RS and CS) in observed particle-size composition in winter and summer samples.

\section{Experimental Design}

The number of colonies of gram-negative, coliform, Streptococcus spp., and Klebsiella spp., and amounts of $\mathrm{DM}$ and $\mathrm{OM}$ were assumed random variables with a Gaussian distribution. Particle size was assumed a compositional variable in which the measurement of any single variable depended on the contributions of all others to the whole characterization (particle-size composition).

Random variables were analyzed using a factorial design with 3 fixed effects, and with one random effect nested within one of the fixed effects. The fixed-effect factors in the experiment were treatment (CS and RS), trial (winter and summer), and day [d 0 (from pile) and d 1 to 7 (after bedding)].

Because each facility does not receive each treatment, facilities were nested within treatments, and trials (1 and 2) interact with treatments. All facilities were free stalls using CS or RS, but facilities were not standardized in terms of the number of cows milked, operations, or other management procedures. Therefore, any effect in the model that includes facilities was a random effect. Day was a fixed effect because the interval was identical for each treatment and interaction, but day did not interact with treatment or trial, because this source of variation was a repeated measure that is compared within each treatment $\times$ trial interaction. The analysis was repeated for each dependent random variable, and for each season. The alpha level of rejection for each comparison was 0.05. Post-ANOVA comparisons of fixed effects were tested with least squares means contrasts where each level of a fixed effect was compared with all other levels. For levels to be considered significantly different, the probability of a type 1 error had to be less than the alpha level of rejection (0.05) for both the $t$-statistic comparison between each pair of levels, and the $F$-test of all comparisons considered in the contrast.

The experimental design for the analysis of variance is:

Treatments: CS and RS

Trial: First and second

Treatment $\times$ Trial

Treatments (Facilities) - random effect

Days: 0 (Pile) through d 1 to 7 (after bedding)
The details of the 1-way ANOVA model used for all treatment-group comparisons are:

(3-way ANOVA with interacting trials, experimental units nested within treatments, and repeated measures over consecutive days):

$$
\mathrm{Y}_{\mathrm{ijky}}=\mu+\tau_{\mathrm{i}}+\varepsilon_{\mathrm{ij}}+\beta \mathbf{1}_{\mathrm{k}}+\beta 2_{\mathrm{y}}
$$

$\mathrm{i}=1,2$ (control or treatment) $\mathrm{j}=1, \ldots . \mathrm{n}$ (facilities) $\mathrm{k}=$ 1,2 (trials) $\mathrm{y}=1, \ldots 8$ (days), where $\mu$ is the (unknown) overall mean, $\tau_{\mathrm{i}}$ is the (unknown) treatment $\mathrm{j}$ effect, $\varepsilon_{\mathrm{ij}}$ are the experimental unit contributions, $\beta 1_{\mathrm{k}}$ are the (unknown) fixed effect of trials, $\beta 2_{\mathrm{y}}$ are the (unknown) fixed effects of repeated measures over consecutive days, and the sum of the treatment effects are

$$
\left(\sum_{j=1}^{n} \tau_{I}=0\right) .
$$

The assumptions in the model are that treatment effects are deviations from the overall mean; treatment and environmental effects are additive; the error variables are mutually independent; and each error variable is normally distributed with a mean of zero and a common variance.

Null hypothesis:

$$
\begin{aligned}
& \text { Ho1: } \tau_{\mathrm{CS}}=\tau_{\mathrm{RC}} \\
& \text { Ho2: } \beta 2_{1}=\beta 2_{2}=\ldots . \beta 2_{\mathrm{y}}
\end{aligned}
$$

Alpha level of rejection: 0.05 .

\section{Particle Size}

The percentages of all size categories were summed for all experimental units within each treatment-trial combination, creating a single discrete distribution of particle sizes for each treatment-trial combination. This distribution is compared among treatment-trial combinations using a non-Gaussian G-test of predicted discrete frequencies in the treatment population compared with the observed frequencies in the control population. Because this comparison is made between the treatment and control populations for 2 separate trials, the alpha level for rejection is set to 0.0224 , so that if the null hypothesis is rejected for both comparisons in a season, the overall alpha level will remain $<0.05$.

The details of the 2-sample test of discrete distributions are:

$$
\mathrm{X}_{\mathrm{i}}=\sigma_{1} e_{i}+\mu \text { and } \mathrm{Y}_{\mathrm{i}}=\sigma_{2} e_{m+j}+\mu
$$


$\mathrm{i}=1, \ldots \mathrm{m}$ (discrete categories) $\mathrm{j}=1, \ldots \mathrm{n}$ (discrete categories)

where $e_{1}, \ldots e_{m+j}$ are unobservable random variables, $\mu$ is an unknown nuisance parameter, and the parameter of interest is the unknown ratio of $\sigma_{1} / \sigma_{2}$.

The assumptions of the model are that the discrete categories are mutually independent.

Hypothesis:

$$
\text { Ho: } \sigma_{1} / \sigma_{2}=1
$$

Alpha level of rejection: 0.0224 .

\section{Transformations}

To compensate for skewed estimates obtained on $\mathrm{d}$ 0 , when bacterial populations were often several orders of magnitude lower than they were over the remainder of the trial, all bacterial population estimates were natural-log transformed based on the formula $\ln (\mathrm{x}+1)$. This transformation improves the fit of skewed data to the characteristics of a Gaussian distribution (Zar, 1996).

All DM and OM percentage estimates were transformed using the formula $\operatorname{Arcsine}(\mathrm{x} \times 0.01)^{0.5}$. This transformation generally improves the fit of percentage data to the characteristics of a Gaussian distribution (Zar, 1996).

\section{RESULTS}

\section{Population Description}

Means and standard deviations for bacterial populations, DM, and OM (random variables) are presented for winter samples in Tables 1 and 2, and for summer samples in Tables 3 and 4.

During the winter trials, samples were collected on 8 consecutive days at 5 facilities with CS, and 4 facilities with RS. At the remaining facilities (1 CS, 2 RS), consecutive samples were collected over a period of at least 6 d. During the summer trials, samples were collected for 8 consecutive days at 6 facilities with CS and 3 facilities with RS. At the remaining facilities (1 CS, 1 RS), consecutive samples were collected over a period of at least $5 \mathrm{~d}$.

It should be noted that, in Tables 1 and 3, the standard deviations on $\mathrm{d} 0$ for several of the variables equal zero for samples from the CS group. Estimates from all facilities were apparently so low for these variables that they were assigned a minimum estimate based on the precision of the technique used to estimate the population levels.

\section{Winter Data}

There was no significant difference in all the bacterial type counts between CS and RS for both d 0 (pile) and d 1 to 7 (Table 1). Therefore, RS and CS had the same bacterial counts when compared at any sampling time. Differences among facilities did explain a significant amount of variation. There was a significant time effect because bacterial counts for gram-negative bacteria, coliforms, and Streptococcus spp. increased between d 0 (pile sand) and $d 1$ to 7 . However, between $d 1$ to 7 , there were no significant changes in bacterial numbers. In the case of Klebsiella spp., bacterial counts on d 0 were lower than on $\mathrm{d} 3$ to 7 , suggesting that Klebsiella spp. counts were slower to increase compared with total coliforms and Streptococcus spp. During the winter, 4 of $7 \mathrm{~d}$ had total daily coliform count means greater than 50,000 (but less than 200,535) cfu/g for CS; and 1 of 7 $\mathrm{d}$ had means greater than 50,000 (but less than 50,156) cfu/g for RS (Table 1). The mean count for Klebsiella spp. for both CS and RS was low for d 1 to $7(<14,569$ cfu/g; Table 1).

The mean DM percentage for CS was higher than RS in the winter samples (Table 2). Dry matter percentages were significantly higher during the second trial than during the first trial. Differences among facilities did explain a significant amount of variation. The mean percentage of DM content did vary over time during the course of the study. Dry matter percentage increased from $\mathrm{d} 0$ to 1 and then decreased between $\mathrm{d} 3$ and 4 for both treatments. This was verified by the contrasts (valid for both treatments), which demonstrated that the mean for $\mathrm{d} 0$ was lower than the means for all other days; the means for $\mathrm{d} 1$ and 4 were lower than the means for $\mathrm{d} 6$ and 7; and there was no significant difference among the means for $\mathrm{d} 1$ to 5 , or $\mathrm{d} 2,3$, 5,6 , and 7 (Table 2).

Recycled sand had a significantly higher percentage of OM with CS, but the magnitude of the difference was small (Table 2). All means for d 1 to 7 were $<0.4 \%$ for CS, and $<1.1 \%$ for RS. Organic matter percentages were significantly higher during the second trial than during the first trial. Differences among facilities did explain a significant amount of variation. The mean percentage of $\mathrm{OM}$ content varied over the course of the study. The contrasts (valid for both treatments) demonstrated that the mean for $\mathrm{d} 0$ was lower than the means for all other days; the mean for $d 1$ was lower than the means for $\mathrm{d} 6$ and 7; and there was no significant difference among the means for $\mathrm{d} 1$ to 5 , or $\mathrm{d} 2$ to 7 (Table 2).

\section{Summer Data}

There was no significant difference in all the bacterial type counts between CS and RS for d 0 (pile) and d 1 
Table 1. Means and standard deviations for bacterial counts (cfu $\times 1000 / g$ of bedding) measured from sand samples collected from facilities using either clean (CS) or recycled sand (RS) during winter.

\begin{tabular}{|c|c|c|c|c|c|c|c|c|c|c|c|c|c|}
\hline \multirow[b]{2}{*}{ Day $^{1}$} & & \multicolumn{3}{|c|}{ Gram-negative bacteria } & \multicolumn{3}{|c|}{ Coliforms } & \multicolumn{3}{|c|}{ Klebsiella spp. } & \multicolumn{3}{|c|}{ Streptococcus spp. } \\
\hline & & $\mathrm{CS}$ & $\mathrm{RS}$ & Contrast $^{2}$ & $\mathrm{CS}$ & $\mathrm{RS}$ & Contrast & $\mathrm{CS}$ & $\mathrm{RS}$ & Contrast & CS & $\mathrm{RS}$ & Contrast \\
\hline \multirow[t]{2}{*}{0} & Mean & 1.9 & 972.7 & $\mathrm{~A}$ & 0.2 & 43.8 & $\mathrm{~A}$ & 0.1 & 0.6 & $\mathrm{~A}$ & 47.1 & 42.9 & $\mathrm{~A}$ \\
\hline & $\mathrm{n}$ & 12 & 12 & & 12 & 12 & & 12 & 12 & & 12 & 12 & \\
\hline \multirow[t]{3}{*}{1} & Mean & 604.6 & 1636.9 & B & 98.1 & 16.3 & B & 1.0 & 1.0 & $\mathrm{AB}$ & 33431.9 & 4911.2 & B \\
\hline & SD & 615.7 & 4083.4 & & 202.4 & 24.4 & & 2.6 & 1.7 & & 31912.8 & 8569.9 & \\
\hline & $\mathrm{n}$ & 12 & 12 & & 12 & 12 & & 12 & 12 & & 12 & 12 & \\
\hline 2 & $\mathrm{n}$ & 12 & 12 & & 12 & 12 & & 12 & 12 & & 12 & 12 & \\
\hline \multirow[t]{3}{*}{3} & Mean & 437.2 & 1417.2 & B & 18.4 & 50.2 & B & 0.5 & 3.0 & B & 29275.0 & 9374.9 & B \\
\hline & SD & 529.7 & 1726.0 & & 18.7 & 84.5 & & 0.7 & 5.2 & & 34732.3 & 15917.3 & \\
\hline & $\mathrm{n}$ & 12 & 12 & & 12 & 12 & & 12 & 12 & & 12 & 12 & \\
\hline \multirow[t]{3}{*}{4} & Mean & 822.4 & 2291.1 & B & 182.0 & 23.7 & B & 11.4 & 1.7 & B & 29590.6 & 9278.1 & B \\
\hline & $\mathrm{SD}$ & 856.4 & 3722.0 & & 288.1 & 30.4 & & 36.2 & 2.5 & & 26867.8 & 16388.8 & \\
\hline & $\mathrm{n}$ & 12 & 12 & & 12 & 12 & & 12 & 12 & & 12 & 12 & \\
\hline \multirow{2}{*}{6} & SD & 1921.7 & 841.8 & & 331.0 & 21.9 & & 42.2 & 2.1 & & 21764.7 & 14027.9 & \\
\hline & $\mathrm{n}$ & 11 & 11 & & 11 & 11 & & 11 & 11 & & 11 & 11 & \\
\hline \multirow[t]{3}{*}{7} & Mean & 2148.3 & 1015.0 & $\mathrm{~B}$ & 47.5 & 25.7 & $\mathrm{~B}$ & 5.4 & 5.1 & B & 24147.8 & 8505.6 & $\mathrm{~B}$ \\
\hline & $\mathrm{SD}$ & 4062.6 & 890.4 & & 101.1 & 33.8 & & 15.7 & 12.2 & & 21431.2 & 16673.9 & \\
\hline & $\mathrm{n}$ & 11 & 9 & & 11 & 9 & & 11 & 9 & & 11 & 9 & \\
\hline
\end{tabular}

${ }^{1}$ Day $0=$ Sand from the pile used to bed freestalls; $d 1$ to 7 = days after bedding.

${ }^{2}$ Contrasts define differences among days only. Means with different letters differ significantly $(P<0.0001)$.

Table 2. Means and standard deviations for OM and DM percentages collected from facilities using clean (CS) or recycled sand (RS) during winter.

\begin{tabular}{|c|c|c|c|c|c|c|c|}
\hline \multirow[b]{2}{*}{ Day $^{1}$} & & \multicolumn{3}{|c|}{$\mathrm{DM}, * * \%$} & \multicolumn{3}{|c|}{$\mathrm{OM}, * * * \%$} \\
\hline & & CS & $\mathrm{RS}$ & Contrast $^{2}$ & $\mathrm{CS}$ & $\mathrm{RS}$ & Contrast \\
\hline \multirow[t]{3}{*}{0} & Mean & 93.62 & 88.5 & $\mathrm{~A}$ & 0.05 & 0.61 & $\mathrm{~A}$ \\
\hline & $\mathrm{SD}$ & 3.35 & 5.03 & & 0.12 & 0.43 & \\
\hline & $\mathrm{n}$ & 12 & 12 & & 12 & 12 & \\
\hline \multirow[t]{3}{*}{1} & Mean & 95.08 & 90.53 & B & 0.11 & 0.97 & B \\
\hline & SD & 1.8 & 4.95 & & 0.12 & 0.42 & \\
\hline & $\mathrm{n}$ & 12 & 12 & & 12 & 12 & \\
\hline \multirow[t]{3}{*}{2} & Mean & 95.9 & 91.08 & $\mathrm{BC}$ & 0.12 & 1.09 & $\mathrm{BC}$ \\
\hline & SD & 2.25 & 4.99 & & 0.16 & 0.32 & \\
\hline & $\mathrm{n}$ & 12 & 12 & & 12 & 12 & \\
\hline \multirow[t]{3}{*}{3} & Mean & 96.44 & 91.2 & $\mathrm{BC}$ & 0.24 & 1.05 & $\mathrm{BC}$ \\
\hline & SD & 2.08 & 3.32 & & 0.24 & 0.30 & \\
\hline & $\mathrm{n}$ & 12 & 12 & & 12 & 12 & \\
\hline \multirow[t]{3}{*}{4} & Mean & 96.07 & 90.23 & B & 0.31 & 0.84 & $\mathrm{BC}$ \\
\hline & SD & 2.13 & 3.24 & & 0.40 & 0.47 & \\
\hline & $\mathrm{n}$ & 12 & 12 & & 12 & 12 & \\
\hline \multirow[t]{3}{*}{5} & Mean & 96.19 & 91.87 & $\mathrm{BC}$ & 0.30 & 0.94 & $\mathrm{BC}$ \\
\hline & SD & 2.09 & 2.73 & & 0.34 & 0.47 & \\
\hline & $\mathrm{n}$ & 12 & 12 & & 12 & 12 & \\
\hline \multirow[t]{3}{*}{6} & Mean & 96.86 & 91.48 & $\mathrm{C}$ & 0.29 & 1.05 & C \\
\hline & SD & 1.78 & 2.75 & & 0.18 & 0.53 & \\
\hline & $\mathrm{n}$ & 11 & 11 & & 11 & 11 & \\
\hline \multirow[t]{3}{*}{7} & Mean & 96.54 & 91.35 & $\mathrm{C}$ & 0.36 & 1.09 & C \\
\hline & SD & 1.86 & 1.84 & & 0.22 & 0.63 & \\
\hline & $\mathrm{n}$ & 11 & 9 & & 11 & 9 & \\
\hline
\end{tabular}

${ }^{1}$ Day $0=$ Sand from the pile used to bed freestalls; $d 1$ to 7 = days after bedding.

${ }^{2}$ Contrasts define differences among days only. Means with different letters differ significantly $(P<0.0001)$.

$* P=0.01$ to $0.05 ; * * P=0.001$ to $0.01 ; * * * P<0.0001$. 
Table 3. Means and standard deviations for bacterial counts (cfu $\times 1000 / \mathrm{g}$ of bedding) measured from sand samples collected from facilities using either clean (CS) or recycled sand (RS) during summer.

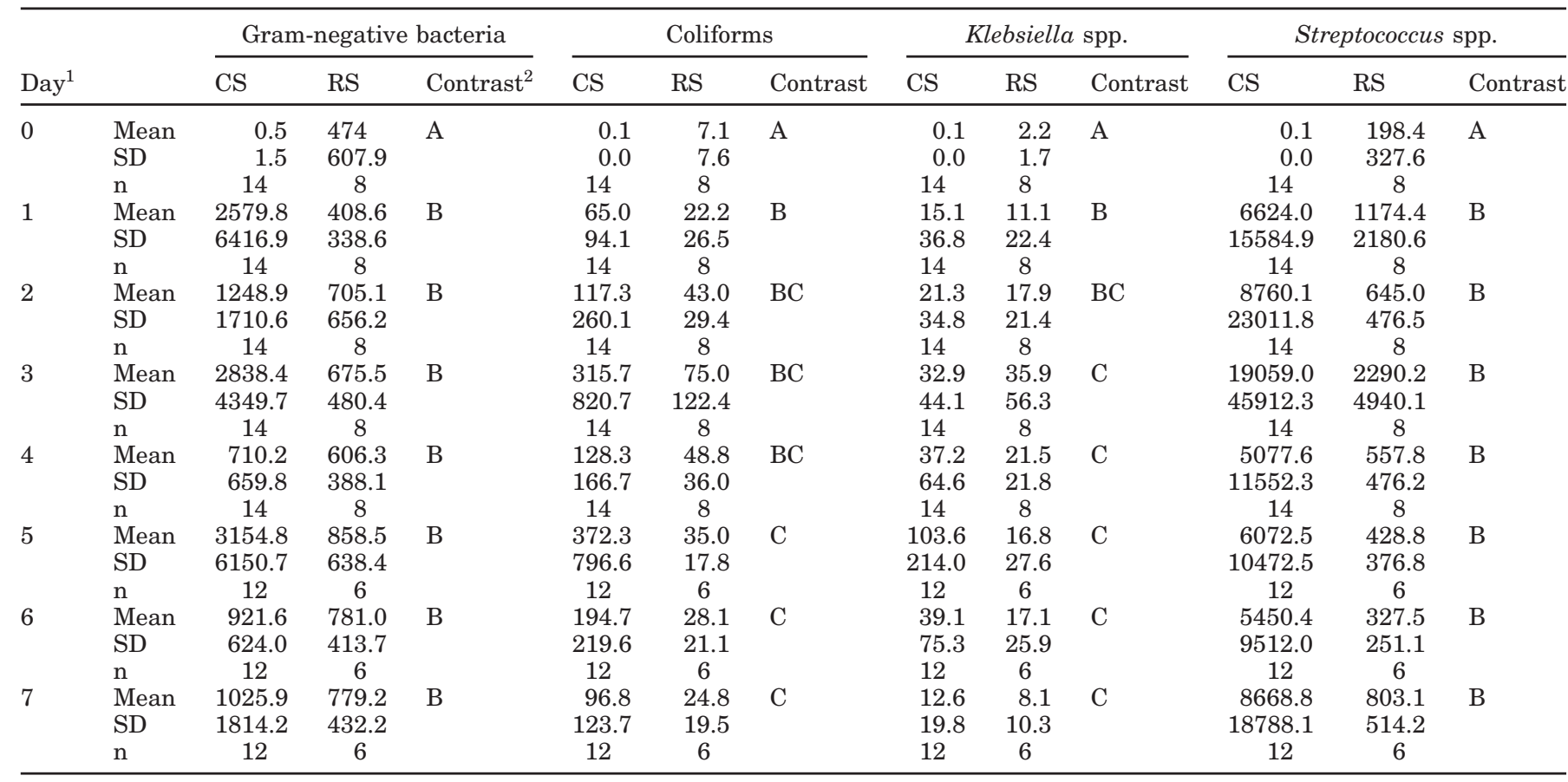

${ }^{1}$ Day $0=$ Sand from the pile used to bed freestalls; $d 1$ to 7 = days after bedding.

${ }^{2}$ Contrasts define differences among days only. Means with different letters differ significantly $(P<0.0001)$.

Table 4. Means and standard deviations for OM and DM percentages collected from facilities using clean (CS) or recycled sand (RS) during summer.

\begin{tabular}{|c|c|c|c|c|c|c|c|}
\hline \multirow{2}{*}{ Day $^{1}$} & & \multicolumn{3}{|c|}{$\mathrm{DM}, * \%$} & \multicolumn{3}{|c|}{$\mathrm{OM}, * * \%$} \\
\hline & & CS & $\mathrm{RS}$ & Contrast $^{2}$ & $\mathrm{CS}$ & $\mathrm{RS}$ & Contrast \\
\hline \multirow[t]{3}{*}{0} & Mean & 93.99 & 89.51 & A & 0.02 & 0.64 & $\mathrm{~A}$ \\
\hline & SD & 4.43 & 3.47 & & 0.04 & 0.20 & \\
\hline & $\mathrm{n}$ & 14 & 8 & & 14 & 8 & \\
\hline \multirow[t]{3}{*}{1} & Mean & 96.57 & 91.63 & B & 0.26 & 0.86 & B \\
\hline & $\mathrm{SD}$ & 2.38 & 3.82 & & 0.32 & 0.32 & \\
\hline & $\mathrm{n}$ & 14 & 8 & & 14 & 8 & \\
\hline \multirow[t]{3}{*}{2} & Mean & 96.81 & 93.61 & $\mathrm{C}$ & 0.3 & 0.99 & B \\
\hline & SD & 2.07 & 3.42 & & 0.33 & 0.29 & \\
\hline & $\mathrm{n}$ & 14 & 8 & & 14 & 8 & \\
\hline \multirow[t]{3}{*}{3} & Mean & 97.27 & 93.27 & $\mathrm{C}$ & 0.38 & 1.20 & $\mathrm{C}$ \\
\hline & SD & 1.85 & 2.79 & & 0.35 & 0.36 & \\
\hline & $\mathrm{n}$ & 14 & 8 & & 14 & 8 & \\
\hline \multirow[t]{3}{*}{4} & Mean & 97.88 & 93.76 & $\mathrm{C}$ & 0.48 & 1.00 & $\mathrm{C}$ \\
\hline & SD & 0.91 & 3.22 & & 0.38 & 0.31 & \\
\hline & $\mathrm{n}$ & 14 & 8 & & 14 & 8 & \\
\hline \multirow[t]{3}{*}{5} & Mean & 97.4 & 93.66 & $\mathrm{C}$ & 0.47 & 1.27 & $\mathrm{C}$ \\
\hline & SD & 2.22 & 1.82 & & 0.44 & 0.36 & \\
\hline & $\mathrm{n}$ & 12 & 6 & & 12 & 6 & \\
\hline \multirow[t]{3}{*}{6} & Mean & 97.67 & 93.47 & C & 0.54 & 1.17 & $\mathrm{C}$ \\
\hline & SD & 1.00 & 2.07 & & 0.45 & 0.51 & \\
\hline & $\mathrm{n}$ & 12 & 6 & & 12 & 6 & \\
\hline \multirow[t]{3}{*}{7} & Mean & 97.59 & 92.96 & $\mathrm{C}$ & 0.53 & 1.28 & $\mathrm{C}$ \\
\hline & SD & 1.98 & 3.32 & & 0.45 & 0.34 & \\
\hline & $\mathrm{n}$ & 12 & 6 & & 12 & 6 & \\
\hline
\end{tabular}

${ }^{1}$ Day $0=$ Sand from the pile used to bed freestalls; $d$ to 7 = days after bedding.

${ }^{2}$ Contrasts define differences among days only. Means with different letters differ significantly $(P<0.0001)$.

$* P=0.01$ to $0.05 ; * * P=0.001$ to $0.01 ; * * P<0.0001$. 
to 7 (Table 3). Therefore, RS and CS had the same bacterial counts when compared at any sampling time. Differences among facilities did explain a significant amount of the variation. There was a significant time effect because bacterial counts for gram-negative bacteria, coliforms, Klebsiella spp., and Streptococcus spp. increased between $\mathrm{d} 0$ and $\mathrm{d} 1$ to 7 . The total number of gram-negative bacteria remained constant from $\mathrm{d} 1$ to 7 . On d 1, coliform counts were lower than on $d 5$ to 7, and Klebsiella spp. counts were lower than on $\mathrm{d} 3$ to 7. Streptococcus spp. counts were constant from d 1 to 7 . During the summer, daily mean coliform counts were greater than 50,000 (but $<372,344$ ) $\mathrm{cfu} / \mathrm{g}$ for CS for 7 of $7 \mathrm{~d}$; and greater than 50,000 (but $<74,985$ ) cfu/ $\mathrm{g}$ in RS for 1 out of $7 \mathrm{~d}$ (Table 2). The daily mean Klebsiella spp. counts for both CS and RS were low for $\mathrm{d} 1$ to 7 (Table 2). The daily mean Klebsiella spp. counts were greater than $50,000 \mathrm{cfu} / \mathrm{g}$ for 1 of $7 \mathrm{~d}$ in CS and 0 out of $7 \mathrm{~d}$ for RS (Table 3 ).

The mean DM percentage of CS was higher than the mean DM percentage of RS in summer samples (Table 4). There were no significant differences among trials or treatment $\times$ trial interactions. However, differences among facilities explained a significant amount of variation. The mean percentage of DM content varied over time during the study. The least squares contrasts (applicable to both treatments) indicated that the mean DM content on d 0 was lower than the mean content on any other day, and the mean content on $d 1$ was lower than on 2 to 7 (Table 4).

Recycled sand had significantly higher OM than did CS, but the absolute magnitude of the difference was small (Table 4). All daily means for OM were $<0.54 \%$ for CS and $<1.28 \%$ for RS. There were differences among treatment $\times$ trial combinations, but they were not consistent among trials. Differences among facilities did explain a significant amount of variation. The mean percentage of OM content did vary over time during the course of the study. The least squares contrasts (valid for both treatments) demonstrated that the mean OM content on d 0 was significantly lower than the mean for all other days, and the mean contents on $d 1$ and 2, although not significantly different from each other, were lower than on d 3 to 7 (Table 4).

\section{Particle Size Analysis}

Recycled sand samples contained a greater percentage of size categories 20 and 60 than CS samples during winter $(P<0.0001$; Figure 1$)$ and summer trials $(P<$ 0.0001; Figure 2).

\section{DISCUSSION}

The results from this study suggest that bacterial populations and numbers are similar for both CS and
RS in either summer or winter. Either CS or RS could safely be used to bed free stalls as the number of coliform and Klebsiella spp. in both CS and RS were below the generally accepted threshold number of $1,000,000$ $\mathrm{cfu} / \mathrm{g}$ thought to cause mastitis. Bernard et al. (2003) reported significantly higher numbers of Bacillus spp. and Klebsiella spp. in RS used for bedding compared with CS, and higher concentrations of Bacillus spp. and Staphylococcus spp. in free stalls bedded with RS compared with CS. Although concentrations of coliforms tended to be higher in RS compared with CS, the total number and types of bacteria in RS were below the threshold number of bacteria thought to cause mastitis and they concluded that RS could be safely used to bed free stalls (Bernard et al., 2003).

A notable finding in this study was the high level of Streptococcus spp. in CS and RS 1 d after sand was placed in the stalls. The numbers of Streptococcus spp. were high by $d$ (Table 1 , Table 3 ), and were constant through $\mathrm{d} 7$ in the winter and summer trials. There was a trend $(P=0.06)$ for Streptococcus spp. to be higher in CS compared with RS in the winter (Table 1). Bernard et al. (2003) reported significantly higher levels of Streptococcus dysgalactiae in free stalls bedded with RS compared with CS. These data are in contrast to reports in the literature suggesting all bacterial populations are lower in sand compared with organic bedding (Fairchild et al., 1982; Hogan et al., 1989). Zdanowicz et al. (2004) reported higher levels of Streptococcus spp. in sand compared with sawdust 1,2 , and $6 \mathrm{~d}$ after stalls were bedded and 10 times higher levels of Streptococcus spp. on the teats of cows bedded with sand compared with sawdust. These data suggest that levels of Streptococcus spp. are as high in sand as in other organic bedding. Further investigations would be required to determine whether RS has a significantly lower number of Streptococcus spp. than CS, or whether certain characteristics of a particular sand type influence the number of Streptococcus spp. In the current study, RS consistently had a significantly greater proportion of coarse particles compared with CS. Coarse particles of sand would have less total surface area for bacteria to attach.

In both winter and summer trials, RS had higher OM and lower DM compared with CS. Although the small order of magnitude difference in OM between CS and $\mathrm{RS}$ was statistically significant, the difference appears to be clinically insignificant because there was no difference in bacterial types and counts in RS and CS. If differences in DM between CS and RS enabled more bacteria to adhere to the teats, DM could be a clinically important risk factor for the development of mastitis. Further studies are needed to compare the actual number of bacteria on the teat ends in cows bedded on CS and RS to understand the effect of DM. 


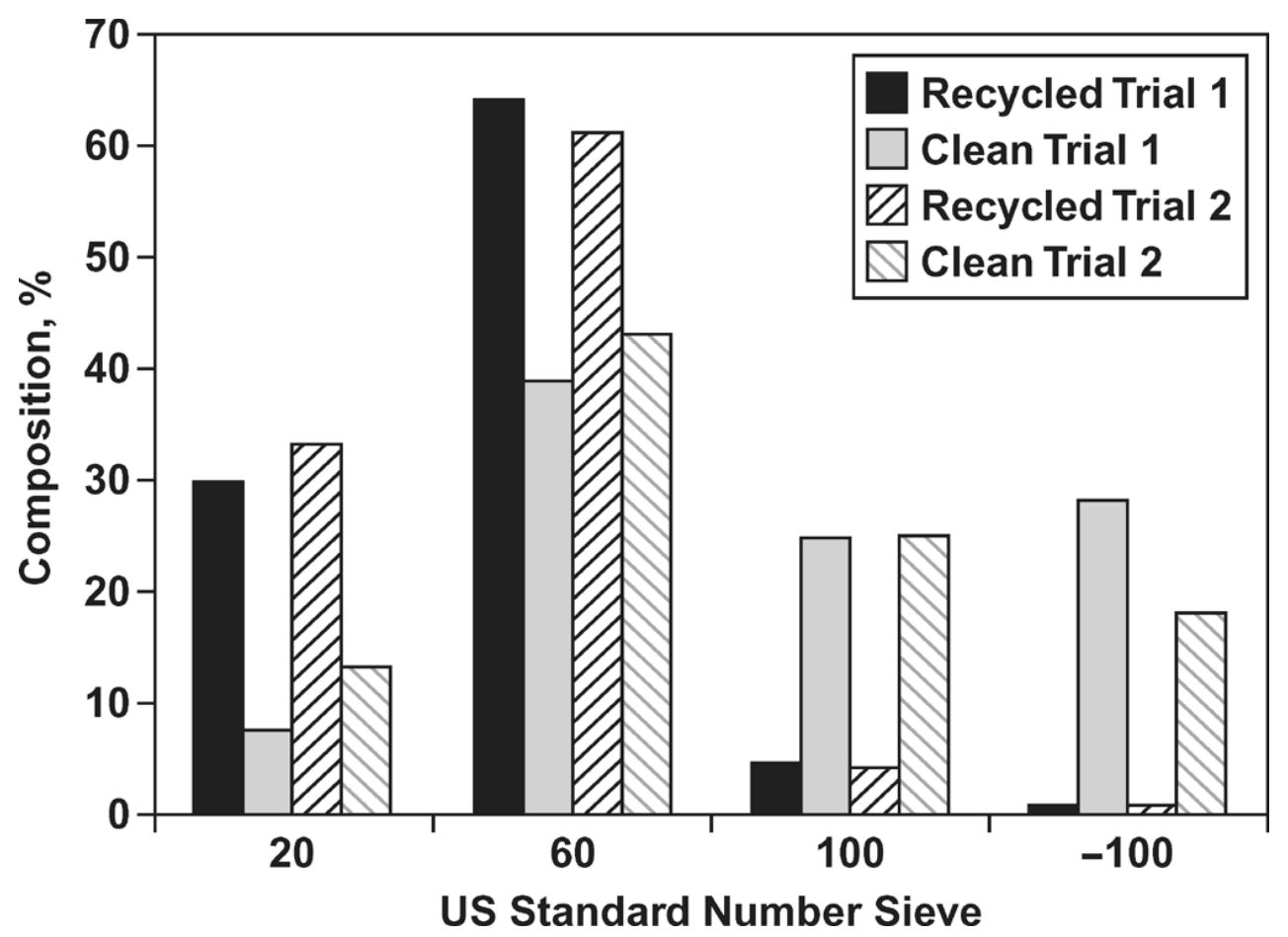

Figure 1. Percentage occurrence of particle-size categories in all treatment-trial samples collected in the winter trials. US Standard Number 20,60, and 100 sieves correspond, respectively, to 850,250 , and $150 \mu \mathrm{m}$ diameter mesh screen sizes. A fourth category ( -100$)$ represents the sand left after dry-sieved through number 20,600, and 100 sieves.

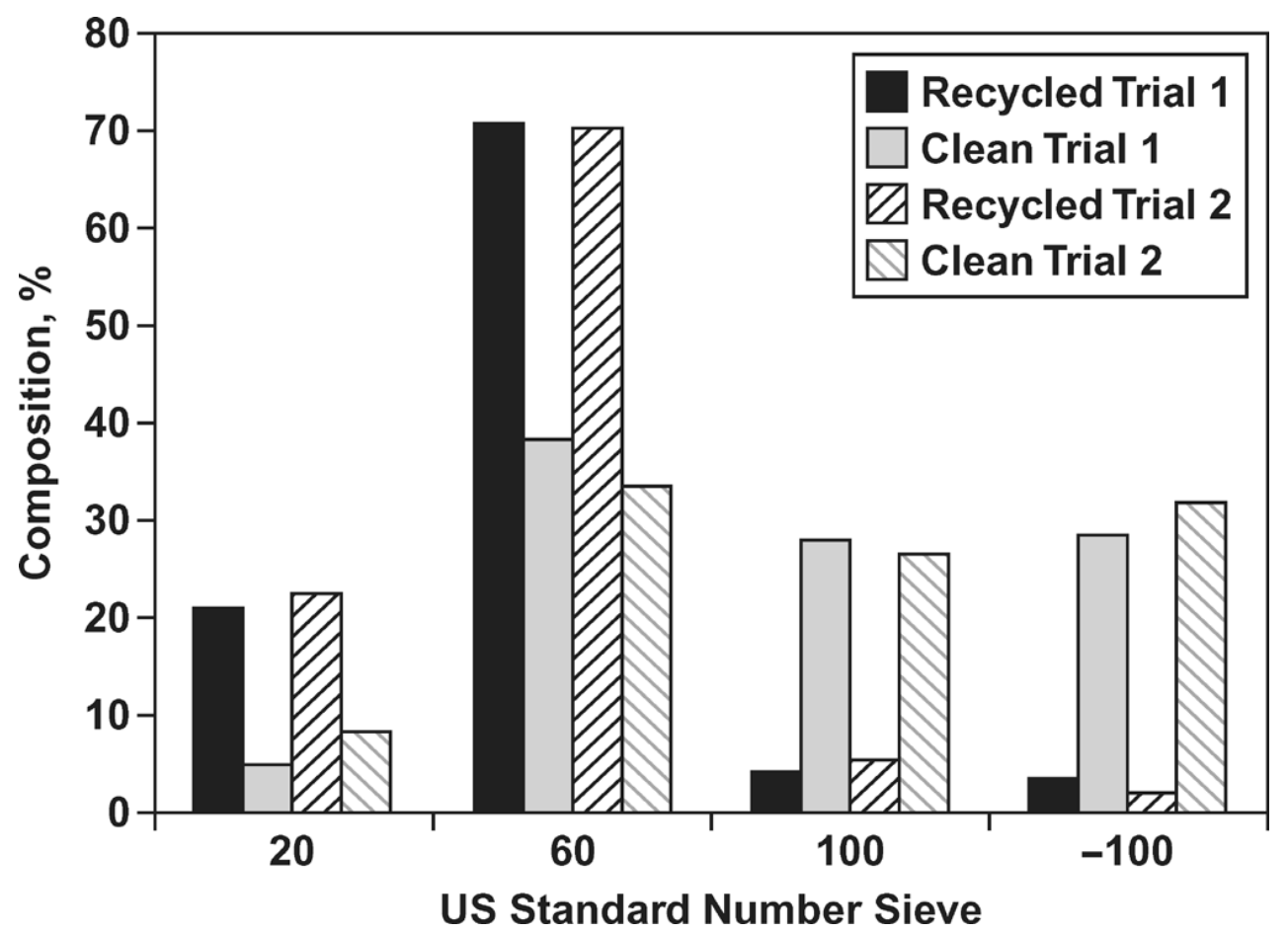

Figure 2. Percentage occurrence of particle-size categories in all treatment-trial samples collected in the summer trials. US Standard Number 20,60, and 100 sieves correspond, respectively, to 850,250 , and $150 \mu \mathrm{m}$ diameter mesh screen sizes. A fourth category ( -100 ) represents the sand left after dry-sieved through number 20,600, and 100 sieves. 
Results from this study suggest that RS is as safe as CS as a bedding material for dairy cows. The results for this study were obtained from multiple herd comparisons, and herd was a significant effect, suggesting that different management systems influence the number and types of bacteria in both CS and RS. Compared with organic bedding, cows bedded on CS or RS should have fewer mastitis infections caused by coliforms. However, there is no evidence from this study to suggest that cows bedded on CS or RS compared with organic bedding would have fewer mastitis events caused by Streptococcus spp. On the contrary, Zdanowicz et al. (2004) reported 10 times more Streptococcus spp. bacteria on teat ends of cows housed on CS compared with sawdust, suggesting that cows on sand could be at increased risk for mastitis caused by Streptococcus spp. because high bacteria levels on the teat ends result in increased environmental mastitis (Hogan et al., 1989).

A consistent finding in this study was a significant increase in bacteria from $\mathrm{d} 0$ to $\mathrm{d} 1$ for gram-negative bacteria, coliforms, Klebsiella spp., and Streptococcus spp. in summer, and for gram-negative bacteria, coliforms, and Streptococcus spp. in winter. Although the number of coliforms and Klebsiella spp. are higher towards the end of the 7-d period in summer, the numbers of coliforms and Klebsiella spp. on d 1 to 7 were lower than those generally found in organic bedding and below accepted threshold values for causing mastitis in both the winter and summer. Because Streptococcus spp. numbers appeared to increase rapidly after either CS or RS is placed in the stalls, more frequent bedding of stalls could be justified. Results from this study would suggest that bedding with CS or RS twice a week could be advantageous, particularly to control Streptococcus spp. Further studies are necessary to identify management factors that might decrease the number of Streptococcus spp. in bedding.

\section{CONCLUSIONS}

Recycled sand can safely be used to bed free stalls on dairy farms. Numbers of gram-negative bacteria, coliforms, Klebsiella spp., and Streptococcus spp. are similar for CS and RS when compared with each other at any time up to $7 \mathrm{~d}$ after bedding.

\section{ACKNOWLEDGMENTS}

The authors gratefully acknowledge the Pennsylvania Department of Agriculture for their financial assistance.

\section{REFERENCES}

AOAC. 1990. Official Methods of Analysis. Vol. I. 15th ed. Association of Official Analytical Chemists International, Arlington, VA.

Bernard, J. K., D. R. Bray, and J. W. West. 2003. Bacterial concentrations and sand usage in free stalls bedded with fresh or recycled sand. Page 153-158 in Proc. National Mastitis Council Annual Meeting, Fort Worth, TX. National Mastitis Counc., Madison, WI.

DeGraves, F. J., and J. Fetrow. 1993. Economics of mastitis and mastitis control. Vet. Clin. North Am. Food Anim. Pract. 9:421-434.

Fairchild, T. P., B. J. McArthur, J. H. Moore, and W. E. Hylton. 1982. Coliform counts in various bedding material. J. Dairy Sci. 65:1029-1035.

Hogan, J. S., K. L. Smith, K. H. Hoblet, D. A. Todhunter, P. S. Schoenberger, W. D. Hueston, D. E. Pritchard, G. L. Bowman, L. E. Heider, B. L. Brockett, and H. R. Conrad. 1989. Bacterial counts in bedding materials used on nine commercial dairies. J. Dairy Sci. 72:250-258.

Natzke, R. P., and B. J. LeClair. 1976. Coliform contaminated bedding and new infections. J. Dairy Sci. 59:2152-2154.

Rendos, J. J., R. J. Eberhart, and E. M. Kesler. 1975. Microbial populations on teat ends of dairy cows and bedding materials. J. Dairy Sci. 58:1492-1500.

Smith, K. L., and J. S. Hogan. 2001. The World of Mastitis. Pages 112 in Proc. 2nd Int. Symp. Mastitis and Milk Quality, Vancouver, Canada. Natl. Mastitis Counc., Madison, WI.

Walkley-Black Method. 1995. Alternate colorimetric procedure involving head dilution. Pages 57-58 in Recommended soil testing procedures for the Northeastern United States. 2nd ed. North East Coordinating Committee on Soil Testing. Agric. Exp. Stn., Univ. Delaware, Newark.

Zar, J. H. 1996. Biostatistical Analysis. Prentice Hall, Upper Saddle River, NJ.

Zdanowicz, M., J. A. Shelford, C. B. Tucker, D. M. Weary, and M. A. G. von Keyserlingk. 2004. Bacterial populations on teat ends of dairy cows housed in free stalls and bedded with either sand or sawdust. J. Dairy Sci. 87:1694-1701. 